\title{
TOOTH LOSS AND TOOTH BRUSHING PRACTISES AMONG ADULTS OF DHARWAD, INDIA
}

\author{
Umesh R. Bilagi', Ramya Kalyanpur², Preetha J. Shetty ${ }^{3}$
}

${ }_{1}^{1}$ Associate Professor, Department of Cardiology, KIMS, Hubli, Karnataka, India.

${ }^{2}$ Assistant Professor, Department of Public Health Dentistry, SDM College of Dental Sciences and Hospital, Dharwad, Karnataka, India. 3 Professor and HOD, Department of Public Health Dentistry, SDM College of Dental Sciences and Hospital, Dharwad, Karnataka, India.

\section{ABSTRACT}

\section{BACKGROUND}

Tooth loss is an undesirable consequence of dental disease or trauma which affects the overall performance of the individual. So, retaining the natural teeth is important and this can be done by correct method of tooth brushing. However, tooth brushing practice varies from each induvial and in different geographic areas too. Thus, the aim of the study was to determine the prevalence of tooth loss and its relationship with tooth brushing practices among the adults of Dharwad district, India.

\section{METHODS}

This cross-sectional survey was conducted on 1, 223 subjects in which 685 were urban and 538 were rural subjects. Multi-stage cluster random sampling method was adopted. Self-designed proforma was used to collect the information on selected sociodemographic factors, tooth brushing habits like material, method and duration of brushing and finally on the number of missing teeth. Primary information was obtained by interview and clinical examination. Data was subjected to statistical analysis using descriptive statics, chi- square test and logistic regression analysis.

\section{RESULTS}

Overall tooth loss was 50.16\%, out of this, $44.66 \%$ and $58.17 \%$ urban and rural subjects had tooth loss respectively. In urban area, type of cleaning $(\mathrm{p}<0.001)$, materials used $(\mathrm{p}<0.001)$, and method of brushing $(\mathrm{p}<0.01)$ were significantly associated with tooth loss. Logistic regression analysis showed that duration of brushing $(\mathrm{p}<0.05$, odds ratio $=1.24)$ was positively associated with tooth loss among the study subjects.

\section{CONCLUSIONS}

This study showed that, there is a significant association between tooth loss and tooth brushing practices. Hence, effective community-based steps should be taken to improve the correct tooth brushing practices which can prevent tooth loss.

HOW TO CITE THIS ARTICLE: Bilagi UR, Kalyanpur R, Shetty PJ. Tooth loss and tooth brushing practises among adults of Dharwad, India. J. Evolution Med. Dent. Sci. 2019;8(14):1098-1102, DOI: 10.14260/jemds/2019/243

\section{BACKGROUND}

Oral health an inseparable component of general health, and it was always neglected as oral diseases are not considered life threatening. ${ }^{1}$ This negative attitude on oral health is generally observed among the people of developing nations like India. The consequence such behaviour towards oral health results in early tooth loss, which in turn leads to impaired quality of life. Hence, preserving the healthy teeth in the oral cavity is important as teeth are essential for chewing, biting, speaking and aesthetics.

Tooth loss a terminal phenomenon of destruction leads to embarrassment and self-consciousness which limit the social interaction and communication. ${ }^{2}$ Along with this there will be decrease in masticatory function, contributing to intake of nutritionally poor diets which in turn poses as a risk factor for several systemic diseases such as cardiovascular diseases and hypertension. ${ }^{3,4}$ Hence, tooth loss is considered to be the dental equivalent of death, recognized as the final outcome of the multi-factorial processes, which can be one of the crucial factors resulting in poor general health. ${ }^{2}$

'Financial or Other Competing Interest': None.

Submission 08-02-2019, Peer Review 26-03-2019,

Acceptance 01-04-2019, Published 08-04-2019.

Corresponding Author:

Dr. Ramya Kalyanpur,

Assistant Professor, Department of Public Health Dentistry,

SDM College of Dental Sciences and Hospital,

Dharwad, Karnataka, India.

E-mail: ramyakalyanpur@gmail.com

DOI: $10.14260 /$ jemds $/ 2019 / 243$
It was also observed that in India, there have been considerable changes in the eating habits, oral hygiene practices and other lifestyle related factors. 5 This has led to the emergence of oral diseases as one of the problems affecting Indian population which has paved the way for substantial increases in tooth morbidity and mortality. ${ }^{6}$

Furthermore, many studies conducted on adult population in India, reveal that dental caries and periodontal disease are the main causes for tooth loss. ${ }^{7}$ But, behavioural aspects like method of tooth brushing, materials used, frequency and duration of tooth brushing play an important role in the prevention and control of those dental diseases which are associated with tooth loss. But these aspects of tooth brushing vary from one geographic area to the other.

Tooth brushing is essential for removing plaque and debris on the tooth surface and this contributes to good oral health. But many people find it difficult to clean their teeth sufficiently and the daily experience in dental practice is that patient's exhibit plaque even though they reportedly engage in oral hygiene. Hence forth there are many unseen tooth brushing factors that result in tooth loss.

Thus, information pertaining to tooth brushing practices and its association with tooth loss helps the health and social policy-makers to take necessary actions to translate knowledge into action programs for the good oral health of the people. Also, in the coming decades, where there is profound increase in the burden of oral diseases leading to tooth loss can be minimized through various preventive programs. At the same time, there is limited information on tooth loss and its relationship with tooth brushing practices 
among Indians and obtaining evidence on this can be a useful tool in monitoring the oral health of the community.

\section{Aim and Objectives}

The present cross-sectional survey was conducted to obtain the baseline data on the prevalence of tooth loss and its association with tooth brushing practices like method, materials, frequency and duration of brushing among the adults of Dharwad district, India.

\section{METHODS}

\section{Study Area}

This cross-sectional survey was conducted in urban and rural areas of Dharwad district, Karnataka, India. Geographically this district is situated in the northern part of Karnataka state with an area of 4, 263 square kilometres. For administrative purpose, this district has been divided into five talukas with 6 urban areas and 390 rural areas. $^{8}$

\section{Study Population, Sample Size and Sampling Procedure}

This survey encompassed subjects belonging to the age group of 18-65 years from urban and rural areas of Dharwad district. As per the district statistical records, sampling frame for age group of 18-65 years was approximately 9 lakhs and they were distributed in the ratio of 56:44 in urban and rural areas respectively. ${ }^{9}$ With this available information following population-based formula was used to determine the sample size (n) for the study.

$$
\mathrm{n}=\frac{\mathrm{Z}^{2} \mathrm{PQN}}{(\mathrm{N}-1) \mathrm{e}^{2}+\mathrm{Z}^{2} \mathrm{PQ}}
$$

$\mathrm{Z}=$ Standard normal at $5 \%$ level of significance or $95 \%$ confidence level (1.96)

$\mathrm{P}=$ Sample proportion (expected proportion $=15 \%$ )

$\mathrm{Q}=$ Alternative proportion (1-P)

$\mathrm{N}=$ Target population size (9 lakhs)

$\mathrm{e}=$ Acceptable error $(2 \%)$

$\mathrm{n}=1,223$

From the above formula, a total sample size (n) of 1, 223 was obtained. Out of this, urban and rural samples were calculated as per the demographic profile of Dharwad district as 685 urban and 538 rural samples.

A multistage, cluster, random sampling procedure was followed, and the study area was divided into two clusters of urban and rural area.

\section{Method of Collection of Data}

Ethical clearance was obtained from the SDM College of dental sciences and hospital, Dharwad for conducting this survey. Followed which an official permission to do the survey was taken from the concerned authorities both in urban and rural areas of Dharwad district.

\section{Inclusion Criteria}

1. Subjects between 18 to 65 years of age.

2. Subjects who are willing to participate in this survey.

\section{Exclusion Criteria}

1. Subjects below the age of 18 years and above 65 years.

2. Subjects who are physically and mentally challenged.

3. Subjects who are systemically compromised.
A house to house survey was conducted, where the subjects were initially interviewed to collect the data on selected demographic factors. Later, participants were asked about their daily tooth brushing practices like type of brushing, materials used for brushing, frequency of brushing, time of brushing, method of brushing and duration of brushing. This was pursued by oral examination to record the total number of missing teeth with the exclusion of third molars. All this information was recorded in a self-designed proforma. Proper infection control measures were followed for oral examination. An average number of 25 to 30 subjects were interviewed and examined per day and it took about 10-15 minutes per subject on most of the occasions.

\section{Statistical Analysis}

The collected data was statistically analysed using descriptive statistics, chi-square test and logistic regression analysis with the aid of statistical software SPSS 20.0 version. Findings were considered statistically significant only if the $P$ value was less than 0.05 .

\section{RESULTS}

It was observed that, out of 1, 223 subjects, 685 (56\%) belonged to urban and 538 (44\%) from rural area. Among the urban subjects, the highest number of study subjects belonged to the age group of $18-28$ years $(n=276,40.29 \%)$ and lowest number of study subjects belonged to the age group of 59-65 years ( $\mathrm{n}=62,9.05 \%)$. Similarly, greater percentage of the rural subjects was between the age group of $18-28$ years $(n=202,37.55 \%)$ and lowest percentage of rural subjects was between the age group of 59-65 years $(\mathrm{n}=$ $55,10.22 \%$ ). It was found that, overall tooth loss was $50.16 \%$ (619). Out of which, $44.67 \%$ (306) urban subjects had tooth loss. Similarly, $58.17 \%$ (313) rural subjects had tooth loss (Graph 1).

Findings of table 2 reveal that, there is a statistically significant association between tooth loss and type of cleaning $(\mathrm{p}<0.001)$, materials used $(\mathrm{p}<0.001)$ and method of tooth brushing $(\mathrm{p}<0.001)$ among the urban adult subjects. However, table 3 reveals that, there is no statistically significant association between tooth loss and tooth brushing practices among the rural adults.

Multiple logistic regression analysis was applied to check the impact of tooth brushing practices on tooth loss. From this it was observed that, there was a positive influence of duration of tooth brushing on tooth loss and the odds ratio was 1.24. This means that, subjects who brushed their teeth more than 2 minutes in a day had more tooth loss.

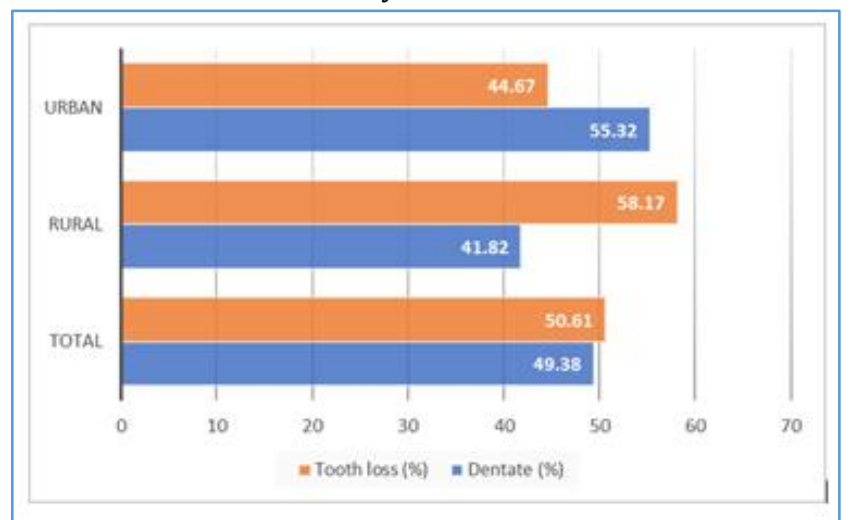

Graph No 1: Tooth loss in relation to location among the study population. 


\begin{tabular}{|c|c|c|c|c|c|}
\hline \multicolumn{2}{|c|}{ Tooth Brushing Practices } & Total Number (n) & $\%$ of Brushing Habits & Tooth Loss (n) & \% Tooth Loss \\
\hline \multirow{5}{*}{ Type of Cleaning } & Brush & 614 & 89.64 & 279 & 45.43 \\
\hline & Finger & 69 & 10.07 & 50 & 72.46 \\
\hline & Twig & 0 & 0 & 0 & 0 \\
\hline & Others & 2 & 0.29 & 2 & 100 \\
\hline & \multicolumn{5}{|c|}{ Chi-square $=20.935, \mathrm{df}=2, \mathrm{p}=0.000^{*}$} \\
\hline \multirow{5}{*}{$\begin{array}{l}\text { Material Used for } \\
\text { Brushing }\end{array}$} & Tooth Paste & 592 & 86.42 & 268 & 45.27 \\
\hline & Tooth Powder & 62 & 9.05 & 42 & 67.74 \\
\hline & Charcoal & 28 & 4.09 & 18 & 64.28 \\
\hline & Others & 3 & 0.44 & 3 & 100 \\
\hline & \multicolumn{5}{|c|}{ Chi-square $=17.253, \mathrm{df}=3, \mathrm{p}=0.00063^{*}$} \\
\hline \multirow{5}{*}{$\begin{array}{l}\text { Frequency of } \\
\text { Brushing }\end{array}$} & No Brushing & 2 & 0.29 & 2 & 100 \\
\hline & Once Brushing & 463 & 67.59 & 219 & 47.3 \\
\hline & Twice Brushing & 217 & 31.68 & 108 & 49.76 \\
\hline & More Than Twice & 3 & 0.44 & 2 & 66.66 \\
\hline & \multicolumn{5}{|c|}{ Chi-square $=3.0082, \mathrm{df}=3, \mathrm{p}=0.39037$} \\
\hline \multirow{4}{*}{$\begin{array}{l}\text { Time of } \\
\text { Brushing }\end{array}$} & Before Meals & 460 & 67.15 & 228 & 49.56 \\
\hline & After Meals & 194 & 28.32 & 91 & 46.9 \\
\hline & In Between Meals & 31 & 4.53 & 12 & 38.7 \\
\hline & \multicolumn{5}{|c|}{ Chi-square $=1.4811, \mathrm{df}=2, \mathrm{p}=0.4768$} \\
\hline \multirow{5}{*}{$\begin{array}{l}\text { Method of } \\
\text { Brushing }\end{array}$} & Horizontal & 258 & 37.66 & 142 & 55.03 \\
\hline & Vertical & 118 & 17.23 & 44 & 37.28 \\
\hline & Circular & 52 & 7.59 & 27 & 51.92 \\
\hline & Combination & 257 & 37.52 & 118 & 45.91 \\
\hline & \multicolumn{5}{|c|}{ Chi-square $=11.503, \mathrm{df}=3, \mathrm{p}=0.0093^{* *}$} \\
\hline \multirow{4}{*}{$\begin{array}{c}\text { Duration of } \\
\text { Brushing }\end{array}$} & $<1$ Minute & 92 & 13.43 & 51 & 55.43 \\
\hline & $<2$ Minutes & 218 & 31.82 & 99 & 45.41 \\
\hline & $>2$ Minutes & 375 & 54.74 & 181 & 48.26 \\
\hline & \multicolumn{5}{|c|}{ Chi-square $=2.8707, \mathrm{df}=2, \mathrm{p}=0.2380$} \\
\hline \multicolumn{6}{|c|}{ Table 2. Tooth Loss in Relation to Tooth Brushing Practices Among Urban Study Subjects } \\
\hline & cant at $0.1 \%$ level & gnificance $(\mathrm{p}<0$. & 1), ** Significant at $1 \%$ & vel of significan & $\overline{0.01)}$ \\
\hline
\end{tabular}

\begin{tabular}{|c|c|c|c|c|c|}
\hline \multicolumn{2}{|c|}{ Tooth Brushing Practices } & Total Number (n) & $\%$ of Brushing Habits & Tooth Loss (n) & \% Tooth Loss \\
\hline \multirow{5}{*}{ Type of Cleaning } & Brush & 376 & 69.89 & 230 & 61.17 \\
\hline & Finger & 159 & 29.55 & 95 & 59.74 \\
\hline & Twig & 1 & 0.19 & 0 & 0 \\
\hline & Others & 2 & 0.37 & 2 & 100 \\
\hline & \multicolumn{5}{|c|}{ Chi-square $=2.9970, \mathrm{df}=3, \mathrm{p}=0.3920$} \\
\hline \multirow{5}{*}{$\begin{array}{c}\text { Material } \\
\text { Used for Brushing }\end{array}$} & Tooth Paste & 331 & 61.52 & 204 & 61.63 \\
\hline & Tooth Powder & 104 & 19.33 & 61 & 58.65 \\
\hline & Charcoal & 96 & 17.84 & 58 & 60.41 \\
\hline & Others & 7 & 1.3 & 4 & 57.1 \\
\hline & \multicolumn{5}{|c|}{ Chi-square $=0.303, \mathrm{df}=3, \mathrm{p}=0.9593$} \\
\hline \multirow{5}{*}{$\begin{array}{c}\text { Frequency of } \\
\text { Brushing }\end{array}$} & No Brushing & 1 & 0.19 & 1 & 100 \\
\hline & Once Brushing & 395 & 73.42 & 235 & 59.49 \\
\hline & Twice Brushing & 137 & 25.46 & 88 & 64.23 \\
\hline & More Than Twice & 5 & 0.93 & 3 & 60 \\
\hline & \multicolumn{5}{|c|}{ Chi-square $=1.524, \mathrm{df}=3, \mathrm{p}=0.67668$} \\
\hline \multirow{4}{*}{$\begin{array}{l}\text { Time of } \\
\text { Brushing }\end{array}$} & Before Meals & 428 & 79.55 & 257 & 60.04 \\
\hline & After Meals & 104 & 19.33 & 64 & 61.53 \\
\hline & In Between Meals & 6 & 1.12 & 6 & 100 \\
\hline & \multicolumn{5}{|c|}{ Chi-square $=3.9777, \mathrm{df}=2, \mathrm{p}=0.13687$} \\
\hline \multirow{5}{*}{$\begin{array}{c}\text { Method of } \\
\text { Brushing }\end{array}$} & Horizontal & 297 & 55.2 & 182 & 61.27 \\
\hline & Vertical & 29 & 5.39 & 13 & 44.82 \\
\hline & Circular & 81 & 15.06 & 49 & 60.49 \\
\hline & Combination & 131 & 24.35 & 83 & 63.35 \\
\hline & \multicolumn{5}{|c|}{ Chi-square $=3.7351, \mathrm{df}=3, \mathrm{p}=0.29154$} \\
\hline \multirow{4}{*}{$\begin{array}{c}\text { Duration of } \\
\text { Brushing }\end{array}$} & $<1$ Minute & 105 & 19.52 & 71 & 67.61 \\
\hline & $<2$ Minutes & 173 & 32.16 & 109 & 63 \\
\hline & $>2$ Minutes & 260 & 48.33 & 147 & 56.53 \\
\hline & \multicolumn{5}{|c|}{ Chi-square $=4.435, \mathrm{df}=2, \mathrm{p}=0.10885$} \\
\hline
\end{tabular}




\begin{tabular}{|c|c|c|c|c|c|c|c|}
\hline Tooth Loss & Regression Coefficient & Standard Error & Z-value & p-Value & Odds Ratio & \multicolumn{2}{|c|}{ 95\% Confidence Interval } \\
\hline Constant & -2.1718 & 0.4823 & -4.5000 & $0.0000^{* * *}$ & 2.79 & -3.1171 & -1.2266 \\
\hline Type of Cleaning & 0.3669 & 0.2658 & 1.3800 & 0.1680 & 0.41 & -0.154 & 0.887 \\
\hline $\begin{array}{l}\text { Materials Used for } \\
\text { Brushing }\end{array}$ & -0.1646 & 0.1608 & -1.0200 & 0.3060 & 0.52 & -0.4799 & 0.1506 \\
\hline $\begin{array}{l}\text { Frequency of } \\
\text { Brushing }\end{array}$ & 0.2993 & 0.1713 & 1.7500 & 0.0810 & 0.79 & -0.0364 & 0.6350 \\
\hline Time of Brushing & -0.1865 & 0.1601 & -1.1600 & 0.2440 & 0.47 & -0.5003 & 0.1273 \\
\hline Method of Brushing & -0.0032 & 0.0501 & -0.0600 & 0.9500 & 0.39 & -0.1013 & 0.0950 \\
\hline Duration of Brushing & -0.1569 & 0.0801 & -1.9880 & $0.0500^{*}$ & 1.24 & -0.3176 & 0.0045 \\
\hline \multicolumn{8}{|c|}{ Table 4. Estimates of Multiple Logistic Regression of Tooth Loss by Tooth Brushing Characteristics } \\
\hline \multicolumn{8}{|c|}{ 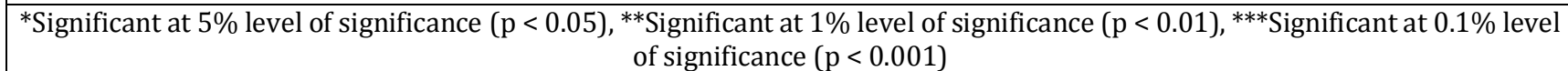 } \\
\hline
\end{tabular}

\section{DISCUSSION}

There is a paucity of information related to oral health and disease status in developing countries like India. Till date, no studies have been reported in the literature on tooth loss and tooth brushing practices of adult population in Dharwad district. Therefore, the present study was conducted to assess association between tooth loss and tooth brushing practices among adults aged 18-65 years in urban and rural areas of Dharwad district.

The present study reveals that the total tooth loss among the study subjects was $50.16 \%$, which means that nearly half of the study population had experienced tooth loss. This indicates that oral health is still neglected in this region and it provides the fact that, there is least practice of preventive approach towards oral health.

Tooth loss was observed more among the urban subjects who are using tooth powder than tooth paste users. This could be due to the more abrasive content of the tooth powder as compared to tooth paste which may initiate the abrasion of tooth surface which left untreated results in tooth loss. However, Addy $\mathrm{M}$ et al reported that toothbrush alone appears to have no effect on enamel and very little on dentine. Most toothpaste also has very little effect on enamel and in normal use would not cause significant wear of dentine in a lifetime of use. Wear of enamel and dentine can be dramatically increased if tooth brushing follows an erosive challenge. ${ }^{10}$ May be that improper materials used for tooth brushing can substantially promote the harm to hard and soft tissues of tooth structure and this can result in tooth loss. Thus, our study findings suggest that, individuals should be cautious in choosing the material used for tooth brushing.

According to Herald Loe et al the most common brushing method by the individual who had never received instructions is a type of horizontal scrubbing technique characterized by back and forth motion on occlusal and buccal surfaces. Vertical methods involving up and down motion of the brush or the sweeping motion of the brush across the gingiva or tooth crown in a rolling or circular motion is considered slightly more advanced techniques. Hence forth, these various methods of brushing practiced by the individuals have a significant effect on the plaque removal from the tooth surfaces. Moreover, individuals with horizontal method of tooth brushing have greater tendency for plaque retention than those with other methods of brushing. Therefore, subjects with the inadequate plaque removal substantiate the development of dental caries and periodontal diseases which if left untreated leads to tooth loss. ${ }^{11}$
In the current survey, urban subjects with horizontal method of tooth brushing had more tooth loss as compared to the subjects who brushed their teeth in vertical, circular or combination of all methods. This may be due to inadequate plaque removal and may also be due to some unseen factors for tooth loss which might not have been recorded in this study. However, studies in the literature had shown that no method of tooth brushing is superior to other, provided the brushing strokes are repeated on all tooth surfaces.

Jagadeesan M reported that subjects who brushed their teeth with finger or twig had experienced more periodontal destruction than tooth brush users. ${ }^{12}$ In the present study urban subjects who brushed their teeth with finger had more tooth loss as compared to tooth brush users. This shows that, type of tooth cleaning also plays a vital role in plaque removal and prevention of plaque related diseases which if inadequately done could enhance the tooth loss.

Rajapakse et al in their systematic review on tooth brushing influence on gingival recession showed that, duration of brushing might be a positive factor that can cause gingival recession. ${ }^{13}$ Similarly, when correlated to the present study results, the long-term accumulated effects of gingival recession caused by improper duration of brushing can lead to tooth loss.

Moreover, there was no statistically significant association between tooth brushing practices and tooth loss among rural study subjects. This does not mean that there is no association between tooth loss and tooth brushing practices among rural adults. But there could be some other unexplored tooth brushing practices which might not have been recorded in this study. Thus, it advised to conduct future studies in this research area especially among the rural subjects which might provide valuable information.

\section{CONCLUSIONS}

There is a significant association between tooth loss and tooth brushing practice. This means that incorrect tooth brushing methods can lead to tooth loss. These findings are more profoundly associated with the longer duration of brushing. Thus, using this baseline data, appropriate public health measures should be taken in this region to inculcate correct tooth brushing practices like right material to be used for tooth brushing, how frequently brushing must be done, correct duration of tooth brushing etc. Along with this it is also recommended to advise the people of this area to get the timely treatment for dental diseases otherwise it may lead to tooth loss. 


\section{REFERENCES}

[1] Gaber P, Martinsson T, Gahnberg L. Incidence of, and reasons for, tooth mortality among mentally retarded adults during a 10-year period. Journal of Acta Odontologica Scandinavica 1999;57(1):55-61.

[2] Steele JG, Sanders AE, Slade GD, et al. How do age and tooth loss affect oral health impacts and quality of life? A study comparing two national samples. Community Dent Oral Epidemiol 2004;32(2):107-14.

[3] Hung HC, Colditz G, Joshipura KJ. The association between tooth loss and the self-reported intake of selected CVD-related nutrients and foods among US women. Community Dent Oral Epidemiol 2005;33(3):167-73.

[4] Taguchi A, Sanada M, Suei Y, et al. Tooth loss is associated with an increased risk of hypertension in postmenopausal women. Hypertension 2004;43(6):1297-300.

[5] US Department of Health and Human Services. Oral health in America: a report of the Surgeon General. Rockville, MD: US Department of Health and Human Services, National Institute of Dental and Craniofacial Research, National Institutes of Health 2000.

[6] Kressin NR, Boehmer U, Nunn ME, et al. Increased preventive practices lead to greater tooth retention. J Dent Res 2003;82(3):223-7.
[7] Hansen BF, Johansen JR. Dental visits, teeth remaining, and prosthetic appliances in a Norwegian urban population. Community Dent Oral Epidemiol 1976;4(5):176-81.

[8] Ground water information booklet, Dharwad district, Karnataka. Government of India, Ministry of water resources, Central ground water board. South Western Region Bangalore. February 2013.

[9] Population Census of India, Issued by District statistical office, Dharwad 2001.

[10] Addy M, Hunter ML. Can tooth brushing damage your health? Effects on oral and dental tissues. Int Dent J 2003;53 Suppl 3:177-86.

[11] Loe H. Oral hygiene in the prevention of caries and periodontal disease. Int Dent J 2000;50(3):129-39.

[12] Jagadeesan M, Rotti SB, Danabalan M. Oral health status and risk factors for dental and periodontal disease among rural women in Pondicherry. Indian J Community Med 2000;25(1):31-8.

[13] Rajapakse PS. McCracken GI, Gwynnett E, et al. Does tooth brushing influence the development and progression of non-inflammatory gingival recession? A systematic review. J Clin Periodontol 2007;34(12):1046-61. 